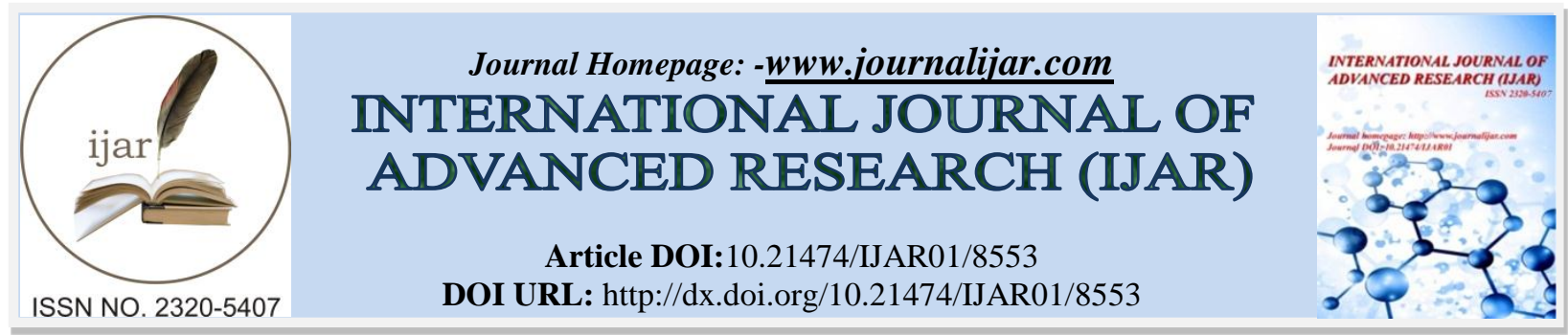

RESEARCH ARTICLE

\title{
NEW POTTERY SURFACE EFFECTS, BY USING RECYCLED INDUSTRIAL WASTES AND WITH ONLY ONE BURN.
}

Faten, Abdel, Fattah, Metwally and Ali.

\section{Manuscript Info}

Manuscript History

Received: 14 December 2018

Final Accepted: 16 January 2019

Published: February 2019

\section{Abstract}

This research aims to have new and special visualizations on pottery surfaces by using non-organic materials of industrial wastes as - iron fillings, copper fillings, broken glass pieces, wires....etc. -and recycling it by adding it on a surface of clay slab prepared for the purpose, as this clay is characterised by high mechanical strength and other physical properties as being unshrinkable during drought and burning, showing no cracks or flows as a result of firing the nonorganic industrial wastes on the surface of the clay, and after drought, the slab is burnt once after adding transparent glaze, the aesthetic effect produced on that surface is being followed then collecting results, evaluate it and explaining observations.

1. Experiments have been made on some slabs made of that prepared clay, as the clay's surface is being treated by using different materials and slabs are burnt on a variety of temperatures (9501050) C. And results showed new and different appearances for the surface.

2. This research is considered as a descriptive experimental research.

3. This research aids having new aesthetic aspects, with new and different style, it also considers the economical value of the product through a single burn, beside recycling nonorganic materials.

Copy Right, IJAR, 2019,. All rights reserved.

\section{Introduction:-}

This research aims to have new and special visualizations on pottery surfaces by using non-organic materials of industrial wastes as - iron fillings, copper fillings, broken glass pieces, wires....etc. -and recycling it by adding it on a surface of clay slab prepared for the purpose, for the slab to be burnt once, after adding transparent glaze , and following the aesthetic change on the surface, then collecting results, evaluate it and explaining observations.

\section{Research's goal:}

Benefiting from specifications of specially specified clay to have a new and different surface effects ,through nonorganic additions on the clay's surface and through a single burn.

\section{Importance of research:}

The importance of the research is about having new and different surface effects, by using inorganic materials and through the economically saving 'single burn'.

\section{Corresponding Author:-Faten.}




\section{Research hypothesis:}

The research assumes the possibility of having new artistic effects on the surface of clay, by adding inorganic materials (industrial wastes) on a surface of clay slab prepared for the purpose, glaze also maybe used above the additions

\section{Problem of the research:}

Problems of the research are focused in having new clay surface effects, with low cost, using recycled industrial wastes and with a single burn.

\section{Research curriculum:}

Research follows the descriptive experimental and analytical curriculum.

\section{Research steps:}

First: Using copper industrial wastes.

Using a copper wire under a transparent paint straight to the surface of the clay:

As a copper wire is put straight to the surface of a wet clay, then transparent paint is applied above the wire .

\section{The sample is burnt at $1050 \mathrm{C}$}

1. Having gathers of glaze inn the gaps produced around the copper wire.

2. Black and White colours of glaze appears (photos 1,2 and 3)

\section{Notes:}

1. The body accepted the paint on the clay's surface after the first burn.

2. No cracks appeared around the copper wirewhich approved that the clay didn't shrink during burn and drought.

3. Gaps around the copper wire are produced, it stored more glaze giving it a special artistic appearence

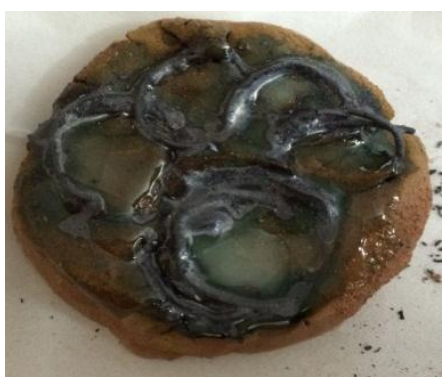

photo no 3:-

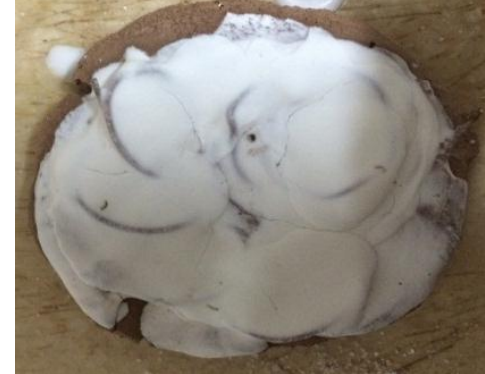

photo no 2:-

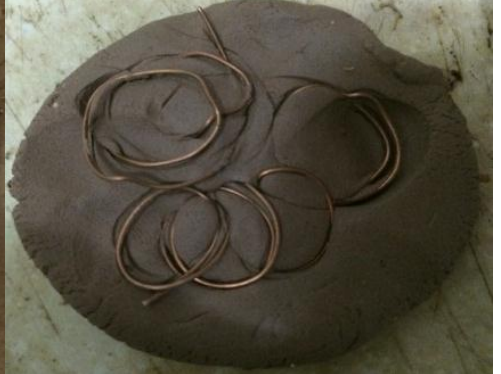

photo no1:-

Using copper fillings directly on the surface of clay:

1. Copper fillings are added on the surface of a slab of improved earth clay.

2. Slab is burnt at $1050 \mathrm{C}$.

3. Copper fillings colour changed to pale black with having glaze's glither on the tips (photos 4,5,6 and 7)

\section{Notes:}

1. The non-burnt ceramic surface accepted the sticking of the iron fillings without cracking or errors during burning and drought.

2. Clay's surface accepted the glass paint without any flaws during burning and drought.

3. Having a special black colour with a different feel that can be aethetically used. 


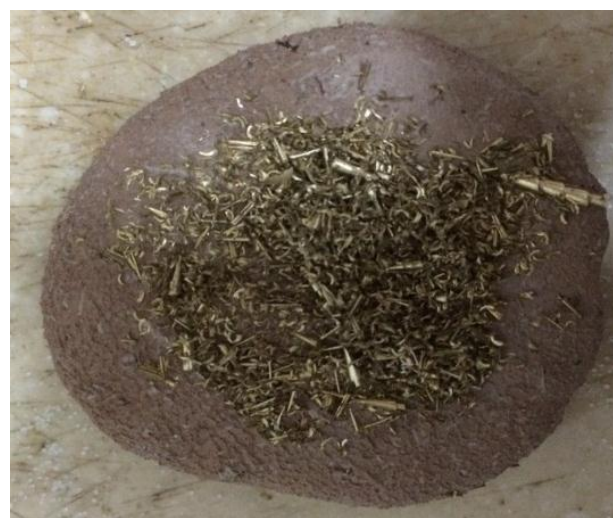

Photo no 4:-

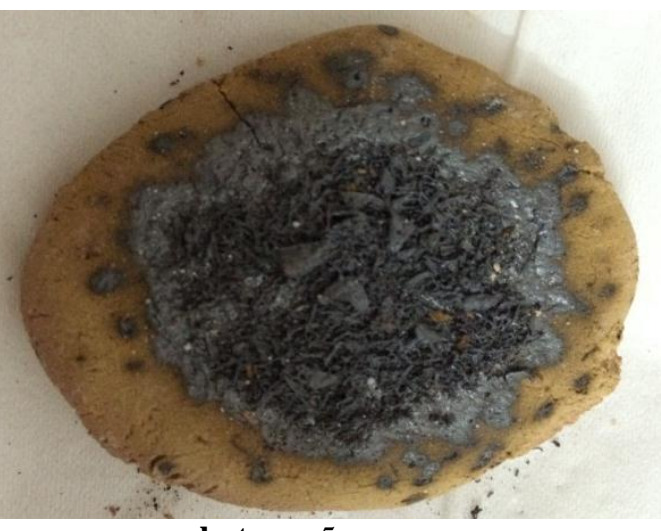

photo no 5:-

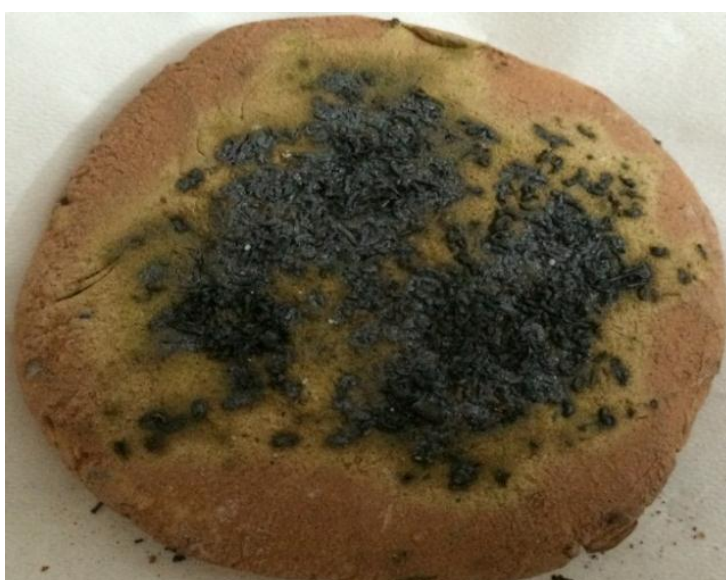

Photo no7:-

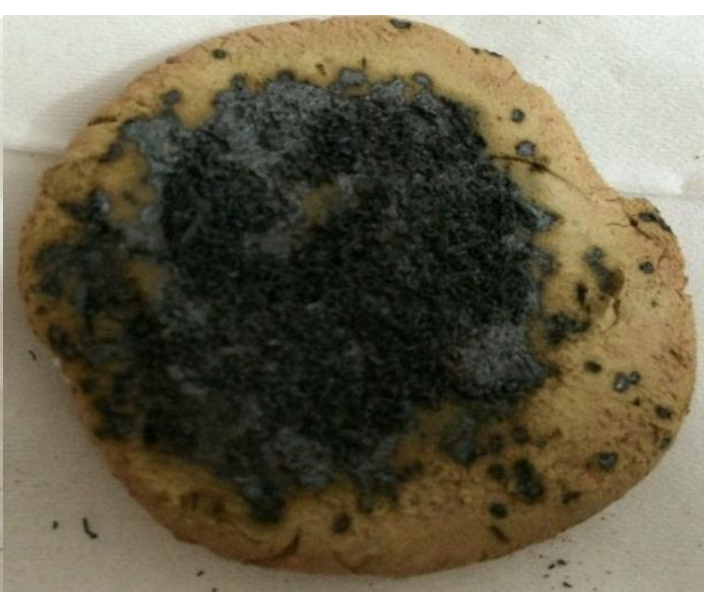

photo no 6:-

Using rough grated iron on the surface of the clay and with transparent glaze above it:

1. Grated iron were put on te surface of developed earth clay slab.

2. Transparent glaze were applied above the grated iron.

3. The slab was burnt at $1050^{\circ} \mathrm{C}$.

\section{Result:-}

Getting shiny black collour with rough texture.
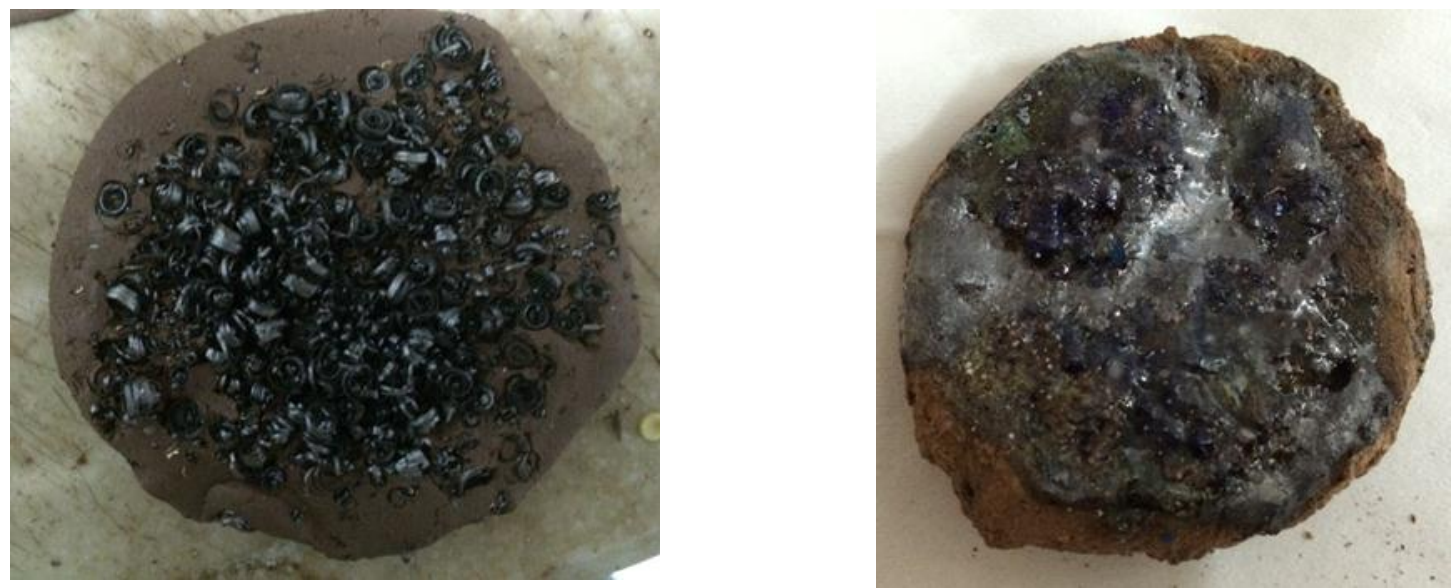
Using broken glass right on the surface of the clay:

1. Glass pieces were implanted on the surface of the improved clay slab.

2. The slab was burnt at $1050^{\circ} \mathrm{C}$.

\section{Notes:}

1. fusion of the glass in it's place without cracks or flaws, which proves the strong mechanical force of the clay which gave it expansion resistance to the obvious glass expansion due to it's fusion.

2. crystal cracking occures to the glass pieces at it's place, due to it's size increase during fusion,proving once more the high mechanical force of the clay as the glass broke but the clay didn't crack.

3 . the decrease of the in-between areas of the clay -between glass pieces- due to the increase of the glass pieces' size during fusion (photos no $10,11 \& 12$ )

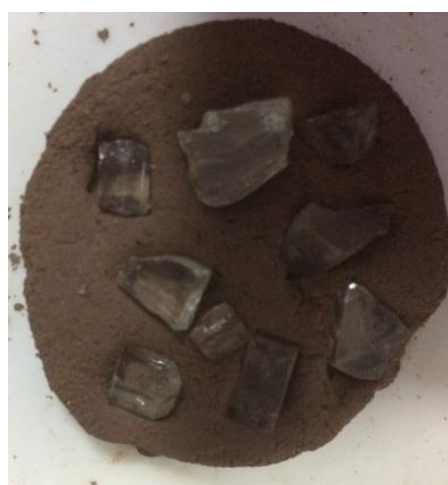

Photo no 12:-

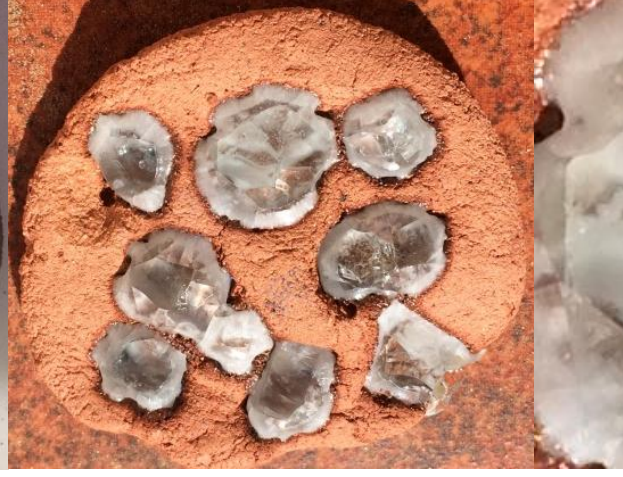

photo no 11:-

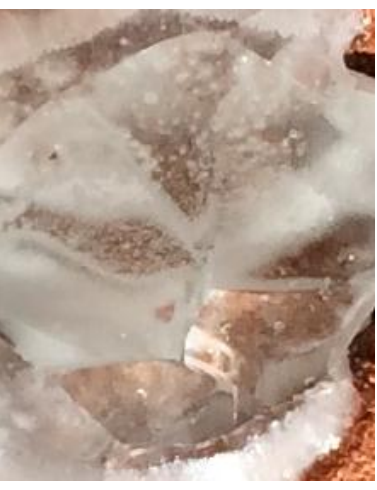

photo no 12:-

\section{Second:}

1. adding two organic materials to the surface.

2. Adding glass pieces also iron pieces to a surface of clay slab.

3. Glass and iron pieces were added side by side randomly.

4. Slab was burnt at $950^{\circ} \mathrm{C}$.

\section{Notes}

1. iron pieces kept its shape above the clay and was fixed.

2. fusion of glass pieces and it crystally broken in order.

3. Some of the glass pieces were melted upon some of the iron pieces so iron pieces appear through the glass.

4. he presence of some bubbles inside the melted glass, mostly produced from some of the steam made by the body during burning, photos 13,14,15

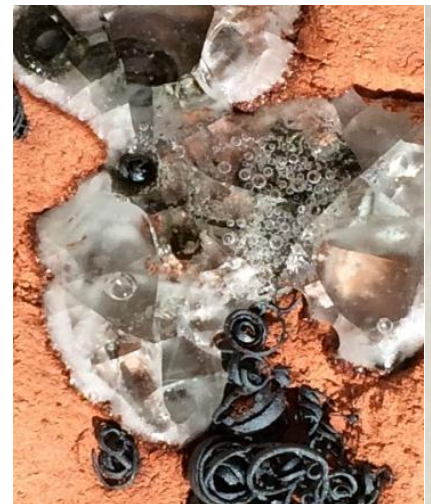

Photo no 15:-

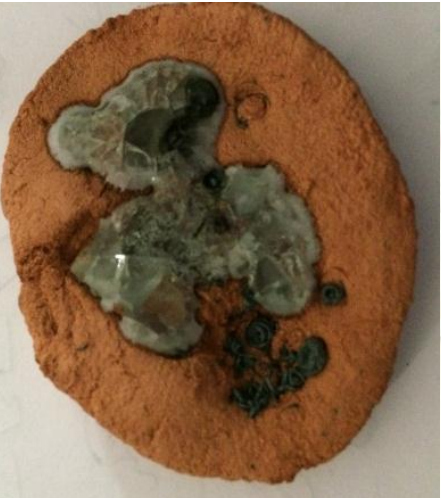

Photo no 14:-

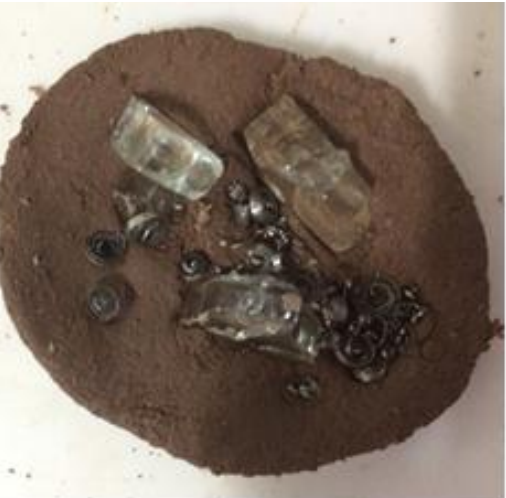

Photo no 13:- 
Improved mud is used as an underlay upon the clay's surface(buiscuit), then adding organic materials under the transparent glaze

1. Mud is added on the buiscuit's surface of the clay slab.

2. Copper fillings are added on the underlay.

3. Laboratory made transparent glaze is added on the surface, the burnt at $1000 \mathrm{C}$.

\section{Notes}

1. the underlay is fused with the biscuit surface

2. black metal color is produced, as a result to the change of the transparent paint combination. (Photos 16,17,18)

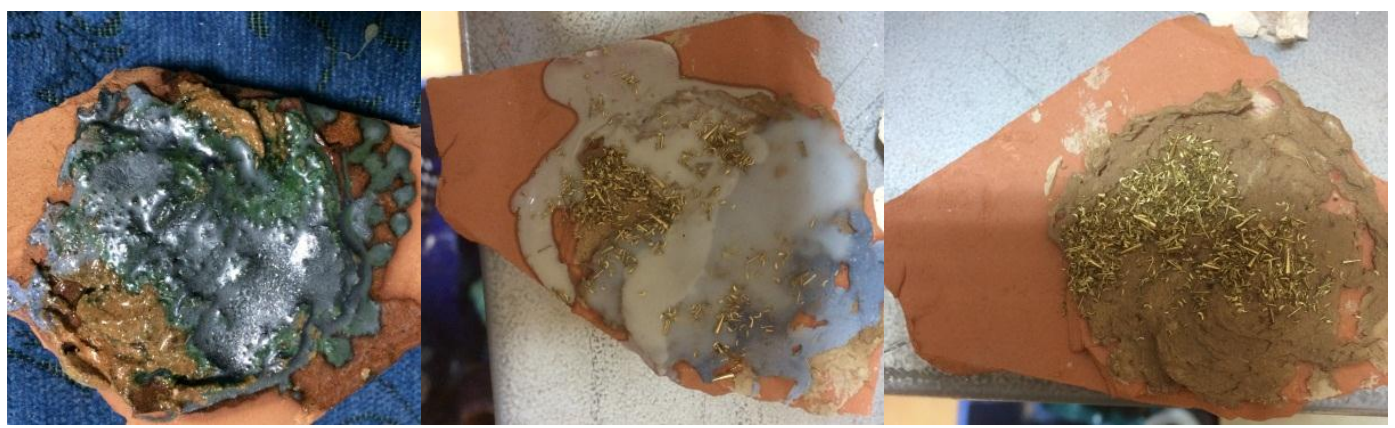

Photo no 18:-

Photo no 17:-

Photo no16:-

\section{Combining broken glass with copper coil.}

1. Glass pieces are randomly added beside the copper coil on the surface of a prepared mud slab.

2. Slab is burnt at $950 \mathrm{C}$.

\section{Notes:}

1. No cracks appeared or any other flows during burn or drought

2. glass is melted and adhered to the surface after burning.

3. some of the melted glass is fused with the copper wire creating green coloured glass

4. the copper wire's colour is changed to black metal colour. (Photos 19, 20)

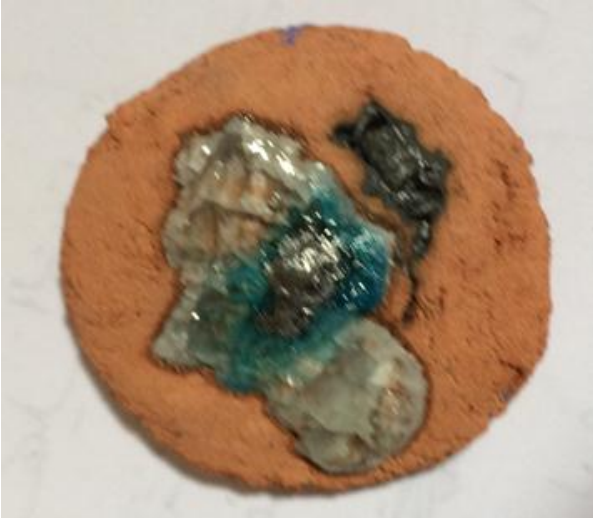

Photo no 20:-

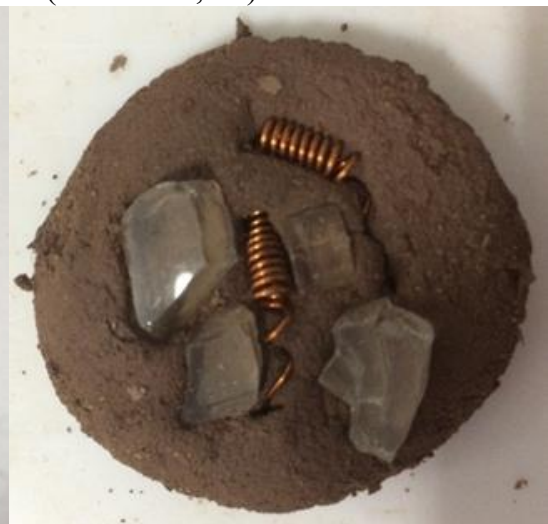

Photo no 19:-

\section{Other experiments:}

getting metal black color by adding transparent paint conainin borax, and havint green color produced from oxidation of copper, due to the fusion of copper fillings to the borders during melting of glaze (phot no. 21) 


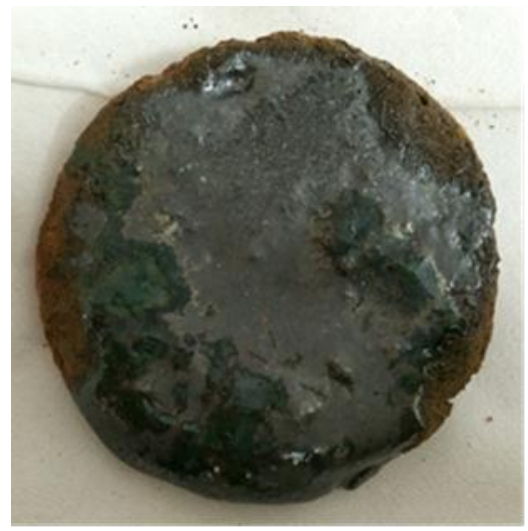

Photo no 21:-

Having a rough black shiny texture, with some areas having metal black colour, using transparent glaze above grated iron with size of $0.5 \mathrm{~mm}^{3}$, which is directly added to the surface of the mud, and finally burnt once at $1050{ }^{\circ} \mathrm{C}$, (photos no. 22,23,24)
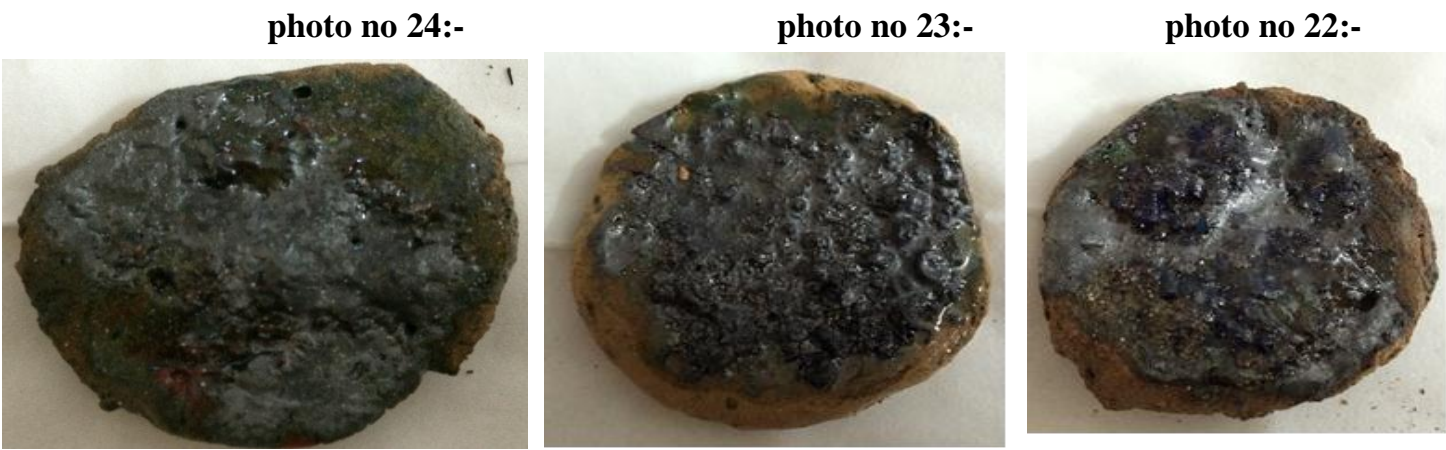

using ceramic pigments above the copper added to the surface of the mud, transparent paint was added, and then burnt at $1050{ }^{\circ} \mathrm{C}$. (photos 25,26$)$

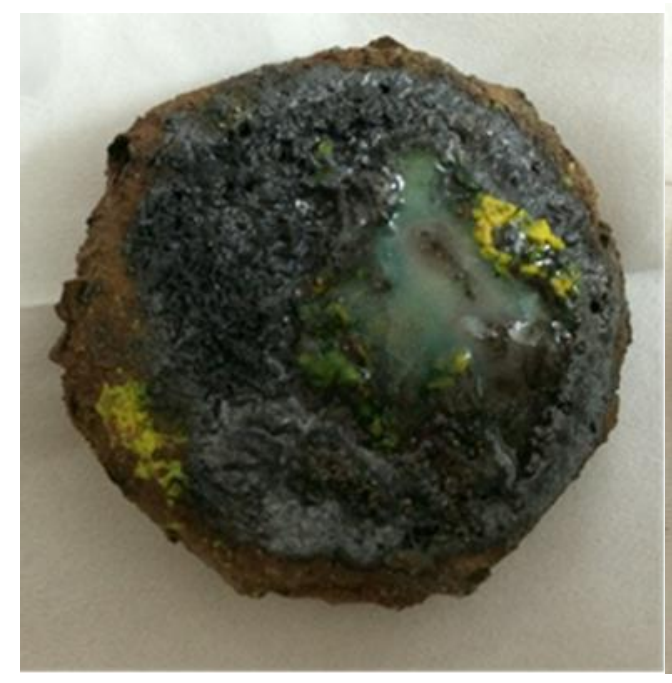

Photo no 25:-

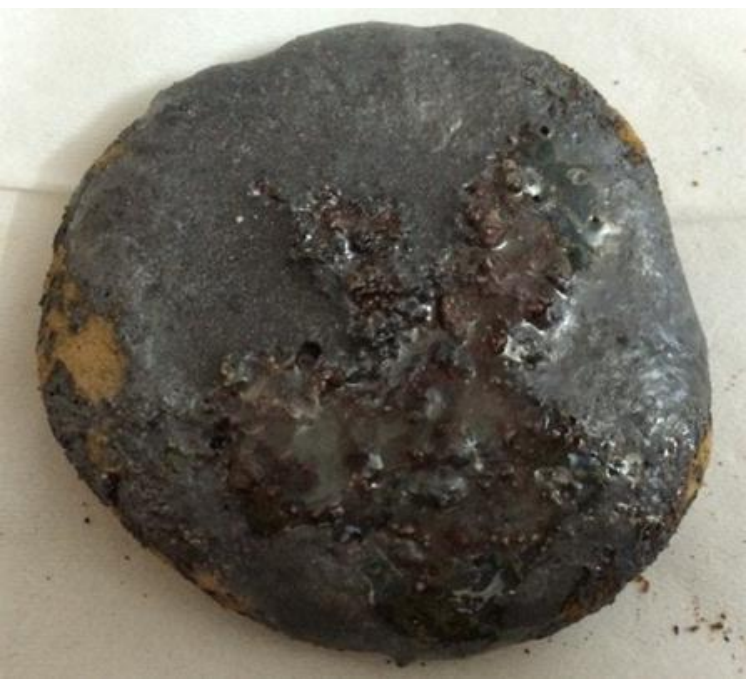

Photo no 26:-

Some uses of previous experiments on some hand made earthenware:

1. A hand made plate made of one slice using earth clay and was burnt at $950{ }^{\circ} \mathrm{C}$. 
2. Prepared layer of mud was added to thee surface of the plate, grated copper was added, also transparent glassy paint was added, then burnt again at $1030{ }^{\circ} \mathrm{C}$.

\section{Results:-}

1. The presence of cracks due to the difference between coefficients of shrinkage of added mud and burnt surface which gave a special artistic effect.

2. Getting green colour effect produced by copper silicate.

3. Getting black metallic color produce by having white laze colour.

4. The general effect on the plate's surface (photo no.27)

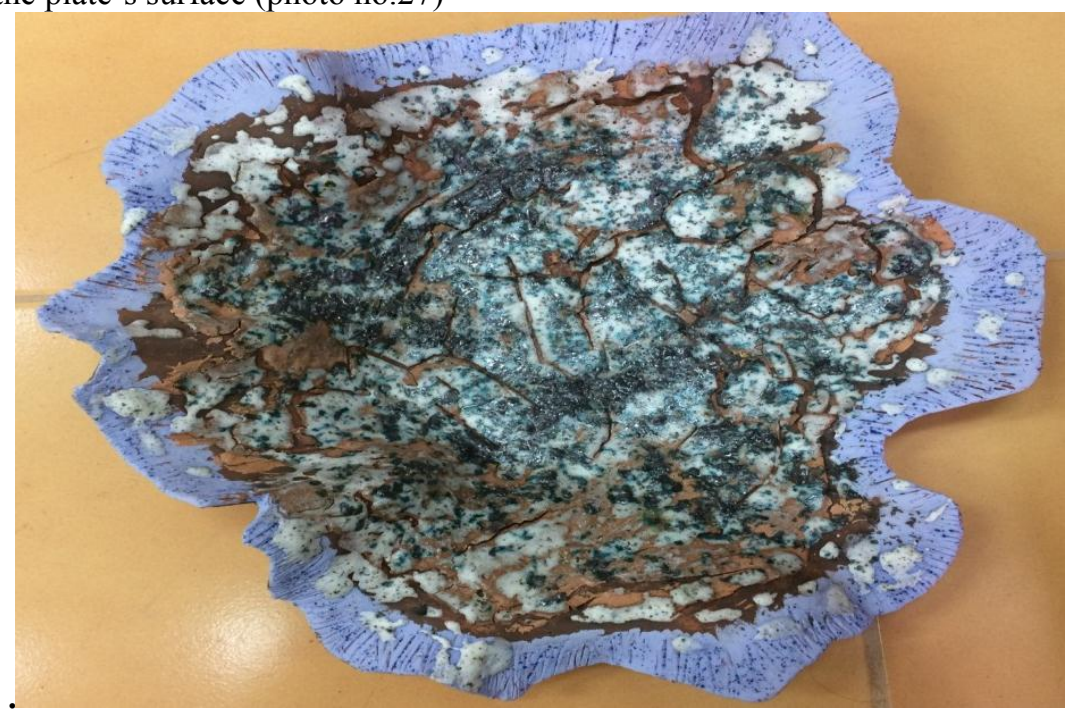

Photo no 27:-

Adding more transparent paint which has drifting speciality during burning -as it has pure borax- to the surface of the previous plate, lead to treatment of cracks after burning it for the third time at $1050^{\circ} \mathrm{C}$, and getting a colourful and new surface effect (photo no. 28).

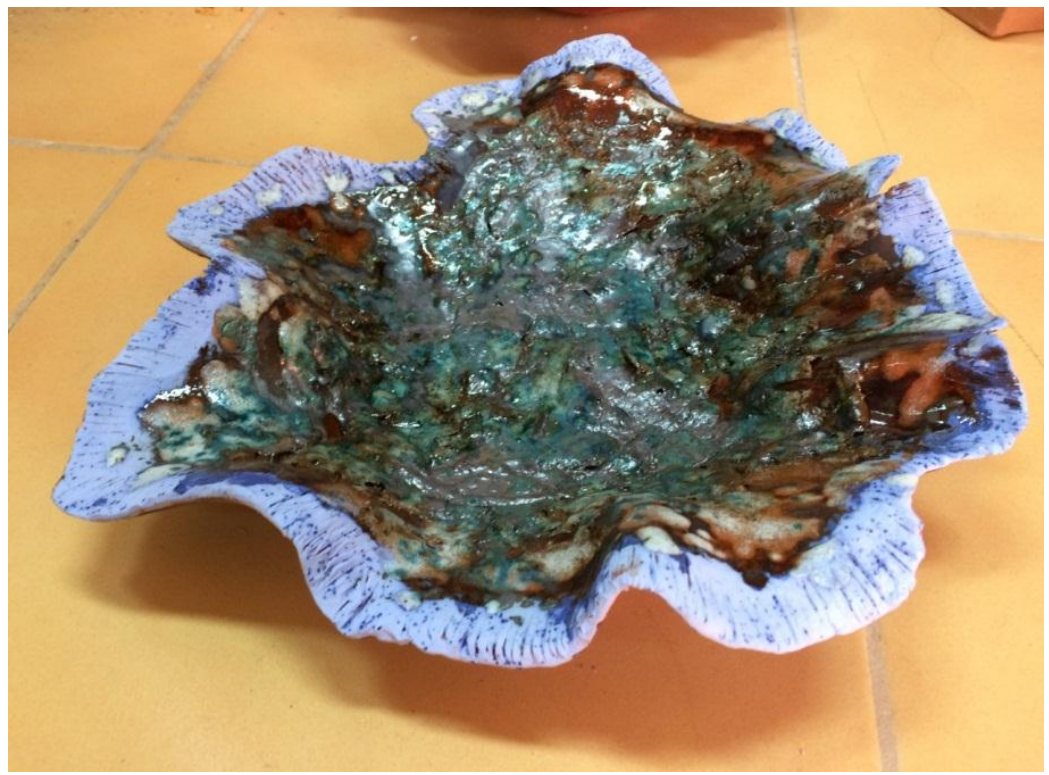

Photo no 28:-

1. Adding little (a light layer) of equipped lining on the surface of a formed plate of mud and burnt at $950^{\circ} \mathrm{C}$. 
2. Grated copper the added in a greater amount, red tincture also added, and then covered with transparent paint.

3. The plate was burnt at $1000^{\circ} \mathrm{C}$.

4. Getting shiny metallic black surface, with the appearance of some blue and green coloured areas due to the different reactions of copper, which changes with the change of the reacted materials, also red color appears due to the addition of the red tincture (photo no. 29)

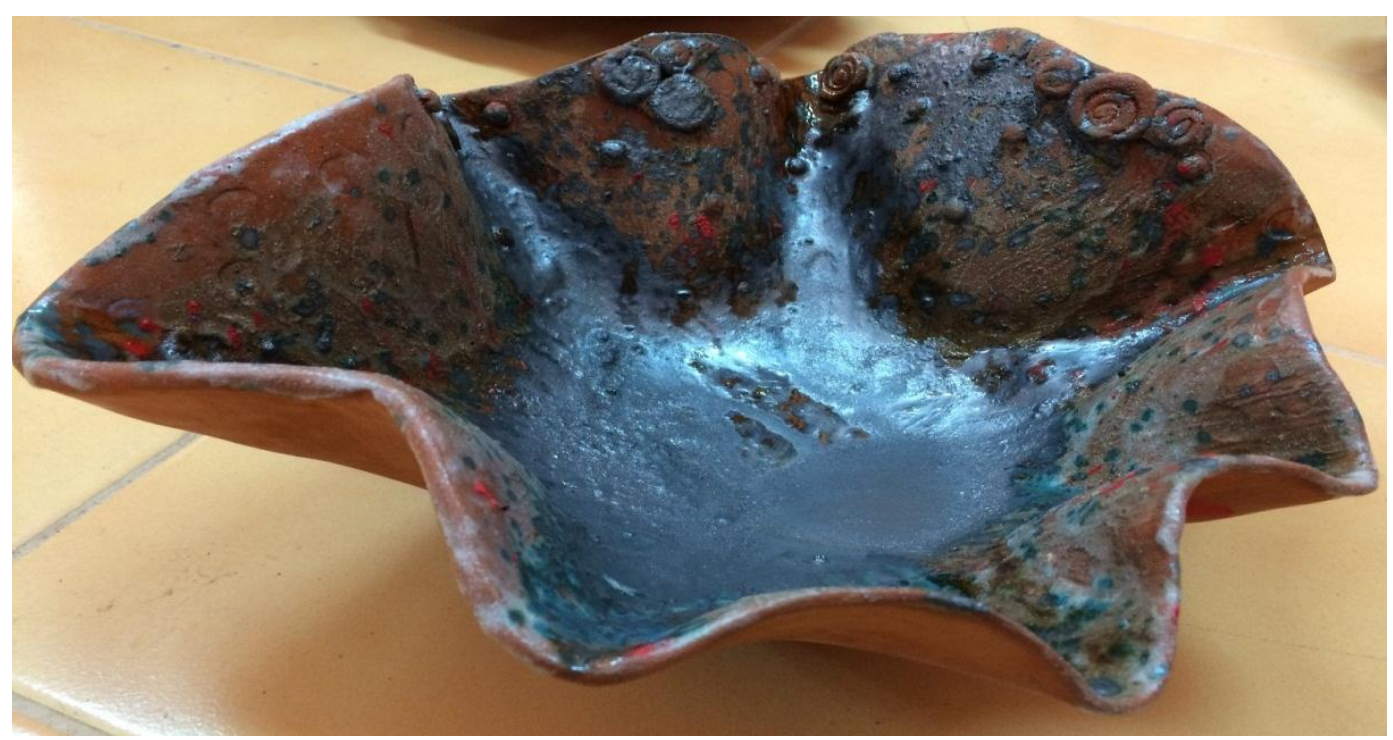

Photo no 29:-

1. Adding prepared underlay on the surface of the earthenware (ceramic) formed from clay by the pottery wheel, and the underlay was added heavily at the nozzle and the neck, without the body.

2. Grated copper were added above the underlay

3. Covering the surface of the shape completely with transparent glaze.

4. Results:

5. Appearance of shiny metal black color at the areas where the underlays added only, which means that the appearance of this color is related to the components of the added underlay.

6. The appearance of green and blue colors on the rest of the surface which doesn't contain the underlay (photo no.30)

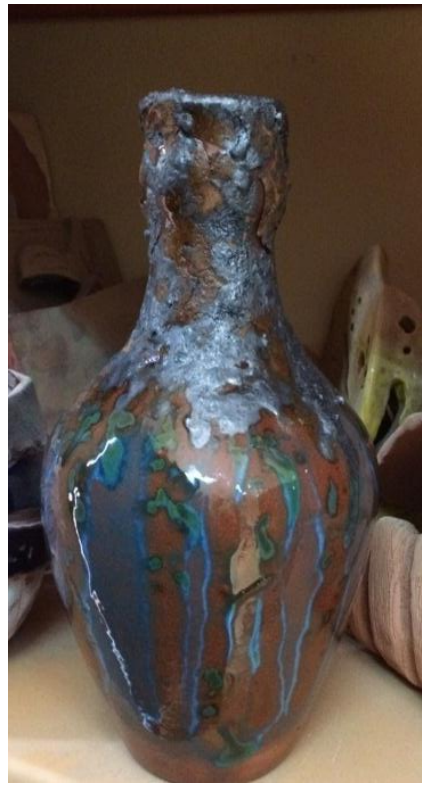

Photo no 30:- 


\section{General results:}

1. Getting a new surface effect in every experiment is related to the texture of the added organic materials.

2. Having shiny black metal color.

3. The ability of getting shiny metal black colour with one burn by adding prepared underlay on the surface of the unburnt shape then adding grated metals and covered with transparent glaze.

4. Economical saving by recycling non-organic industrial wastes.

5. Economical saving using only one burn for a glassy product.

\section{Recommendations:}

1. Applying some of those experiments on suitable art pieces that is made from the same prepared clay for the purpose.

2. Applying some of these experiments on industrial wastes.

3. Running new experiments using new organic materials and follow up the results.

4. Making other experiments at the same framework using other organic materials.

5. Making new experiments in which organic and no-organic materials are mixed and follow up with the results.

\section{References:-}

1. Frank Hamer, The Potter's Dictionary of Materials and Techniques ( University Pennsylvania Press; 4th

2. edition, 1997).

3. James C.Watkin, alternative kilns \& firing technique, : Raku * Saggar * Pit

4. Barrel (A Lark Ceramics Book, Paperback, 2006).

5. Maureen mills, surface design for ceramics ( Lark Crafts, 2011).

6. John Britt ,the complete guide to MID-RANGE GLAZES : Glazing and Firing at Cones 4-7 (Lark Ceramics

7. Books) Hardcover, 2014) 